\title{
MONITORING SUHU DAN KELEMBABAN MENGGUNAKAN SMS GATEWAY PADA PROSES FERMENTASI TEMPE SECARA OTOMATIS BERBASIS MIKROKONTROLER
}

\author{
Denny Wijanarko', Soviatul Hasanah ${ }^{2}$ \\ ${ }^{1,2}$ Jurusan Teknologi Informasi, Politeknik Negeri Jember \\ 1dennywijanarko@gmail.com
}

\begin{abstract}
Abstrak
Dalam pembuatan tempe di pengaruhi oleh banyak hal terutama dipengaruhi oleh perubahan cuaca . Pada cuaca dingin, tempe biasanya ditutupi dengan kain atau penutup lain agar suhu fermentasi tempe tetap stabil sehingga proses fermentasi tempe dapat berlangsung secara normal. Tetapi dengan cara ini ,produsen tempe tidak mengetahui berapa suhu dan kelembabannya. Dengan berkembangnya teknologi mikrokontroler saat ini dibutuhkan suatu alat yang dapat mendeteksi suhu dan kelembaban, Sistem pengendalian sangat diperlukan didalam dunia industri untuk menghasilkan produk yang bagus maka diperlukan suatu sistem pengendalian yang stabil. Pada alat ini pengontrolan sistem dilakukan oleh Mikrokontroler Arduino UNO yang mempunyai input berbentuk sensor sht11, sensor ini akan mendeteksi suhu dan kelembaban yang berada dalam Inkubator dan menampilkannya pada LCD dan memonitoring melalui SMS Gateway. Inkubator menggunakan sebuah Lampu yang berfungsi sebagai pemanas dengan cara kerja mengeluarkan panas pada Inkubator, dan menggunakan 4 buah tombol setting yang berfungsi sebagai pengatur suhu dan kelembaban. Pengaturan batas suhu dan kelembaban di atur didalam program juga dapat di ubah menggunakan tombol yang ada di mikrokontroler.
\end{abstract}

Kata Kunci : Tempe,monitoring, suhu, kelembaban

\section{Pendahuluan}

Salah satu makanan tradisional Indonesia yang mempunyai kandungan gizi sangat baik adalah tempe, yang dihasilkan dari proses fermentasi kedelai. Pada umumnya, dalam pembuatan tempe para produsen tempe masih menggunakan cara manual. Pada cuaca dingin, tempe biasanya ditutupi dengan kain atau penutup lain agar suhu fermentasi tempe tetap stabil sehingga proses fermentasi tempe dapat berlangsung secara normal. Tetapi dengan cara ini, produsen tempe tidak mengetahui berapa suhu dan kelembabanya. Sehingga dibutuhkan suatu alat yang dapat mendeteksi suhu dan kelembaban didalam inkubator pembuatan tempe. Alat pendeteksi ini memanfaatkan modul rangkaian sensor suhu dan kelembaban SHT 11. Pada alat ini pengontrolan sistem dilakukan oleh mikrokontroler Arduino UNO. Kontroler yang digunakan adalah jenis on-off yang dimaksudkan untuk mengaktifkan aktuator yang digunakan. Ketika temperatur dari sensor sudah sesuai dengan input maka frekuensi tegangan akan disesuaikan, sehingga temperatur tidak akan berubah-ubah. Alat pendeteksi ini dapat membantu dalam proses pembuatan tempe, dan dengan sistem monitoring mempermudah dalam pengawasan

suhu dan kelembababn dengan jarak jauh, sehingga proses tersebut dapat berhasil tepat waktu dan dihasilkan tempe yang berkualitas. Hasil produksi tempe akan stabil dan tepat waktu sesuai yang diharapkan. Dengan adanya alat kontrol suhu dan kelembaban ini diharapkan produsen tempe dapat meningkatkan produknya sehingga dapat memuaskan konsumen.

Berdasarkan latar belakang diatas, maka peneliti akan membuat suatu alat yang mampu mendeteksi suhu dan kelembaban pada proses fermentasi tempe, dengan alat tersebut juga dapat mengendalikan suhu dan kelembaban secara otomatis. Hal inilah yang melatar belakangi peneliti untuk mengambil tema ini dalam penelitian yang berjudul "Monitoring Suhu dan kelembaban Menggunaka SMS Gateway pada Proses Fermentasi Tempe Secara Otomatis berbasis Mikrokontroler "

Tujuan

Tujuan dari penelitian ini adalah:

1. Untuk mengetahui cara merancang sebuah perangkat berbasis mikrokontroler yang dapat memonitoring suhu dan kelembaban didalam inkubator fermentasi tempe.

2 Untuk memonitoring suhu dan kelembaban didalam inkubator fermentasi tempe dengan jangkauan jarak jauh. 
3 Untuk mengontrol suhu dan kelembaban pada proses fermentasi tempe menggunakan lampu secara otomatis.

\section{Tinjauan Pustaka}

\subsection{Monitoring}

Monitoring adalah pengawasan yang berarti proses pengamatan, pemeriksaan, pengendalian dan pengoreksian dari seluruh kegiatan yang ingin diketahui

\subsection{Suhu dan Kelembaban}

\subsubsection{Suhu}

Suhu adalah besaran yang menyatakan derajat panas dingin suatu benda dan alat yang digunakan untuk mengukur suhu adalah thermometer. Dalam kehidupan sehari-hari masyarakat untuk mengukur suhu cenderung menggunakan indera peraba. Tetapi dengan adanya perkembangan teknologi maka diciptakanlah termometer untuk mengukur suhu dengan valid.

\subsubsection{Kelembaban}

Kelembaban udara/ legas udara adalah jumlah kandungan uap air yang ada dalam udara. Kandungan uap air di udara berubah-ubah bergantung apda suhu Makin tinggi suhu, makin banyak kandungan uap airnya. Alat pengukur kelembapan udara adalah higrometer.

\subsection{SMS GATEWAY}

SMS gateway adalah sebuah perangkat yang menawarkan layanan transit SMS, mentransformasikan pesan ke jaringan selular dari media lain, atau sebaliknya, sehingga memungkinkan pengiriman atau penerimaan pesan SMS dengan atau tanpa menggunakan ponse (Andris Faesal : 2012).

\subsection{Fermentasi Tempe}

Fermentasi adalah proses yang memanfaatkan kemampuan mikroba untuk menghasilkan metabolit primer dan metabolit sekunder dalam suatu lingkungan yang dikendalikan. Fermentasi merupakan atau aplikasi tertua dari bidang bioteknologi pada mulanya istilah fermentasi di gunakan untuk menunjukkan proses pengubahan glukosa menjadi alkohol yang berlangsung secara anaero.

\subsection{Mikrokontroler}

Mikrokontroler adalah perangkat komputasi kecil yang terdiri dari sebuah IC dengan microprosesor didalamnya, memori program (ROM), memori serba guna (RAM), bahkan ada beberapa jenis mikrokontroler yang memiliki fasilitas ADC,PLL,EEPROM yang dan dapat mengatur input dan output dari alat lain. Mikrokontroler juga disebut suatu chip cerdas yang menjadi tren dalam pengendali dan otomasi. (Agus, 2007). Tempe dibuat dengan cara fermentasi, yaitu dengan menumbuhkan kapang Rhizopus oryzae pada kedelai matang yang telah dilepaskan kulitnya. Inkubasi / fermentasi dilakukan pada suhu 250-37o C selama 36-48 jam. Selama inkubasi terjadi proses fermentasi yang menyebabkan perubahan komponen-komponen dalam biji kedelai. Persyaratan tempat yang dipergunakan untuk inkubasi kedelai adalah kelembaban, kebutuhan oksigen dan suhu yang sesuai dengan pertumbuhan jamur(Hidayat, dkk. 2006). Fermentasi dilakukan pada temperatur kamar $\left(25^{\circ} \mathrm{C}\right)$. Menurut Hui (2004) temperatur optimal untuk melakukan fermentasi adalah $25-37^{\circ} \mathrm{C}$ dengan kelembaban relatif terbaik pada $70-80 \%$. Pada temperatur sedang $\left(31^{\circ} \mathrm{C}\right)$ dan temperatur tinggi $\left(37^{\circ} \mathrm{C}\right)$ lebih dianjurkan untuk proses fermentasi, karena pada temperatur tersebut, kadar vitamin B12 lebih tinggi daripada fermentasi pada temperatur rendah $\left(25^{\circ} \mathrm{C}\right)$.

\section{Metode Penelitian}

\section{a. Metode Kegiatan Penelitian}

Dalam merancang dan membuat implementasi Sistem Monitoring Suhu dan Kelembaban pada proses fermentasi tempe secara otomatis, penulis menggunakan 3 metode yang meliputi :

1. Mendengarkan Produsen yaitu dengan cara mewawancarai secara langsung produsen tempe serta meminta data pada proses fermentasi tempe dan mencari studi literatur sebagai penunjang pada sistem.

2. Membuat dan Memperbaiki Prototype yaitu merancang sistem dan merakit sistem serta merancang program sehingga prototype bisa terselesaikan secara baik dan benar sehingga dapat diterapkan secara langsung pada publik.

3. Produsen Menguji Coba Prototype yaitu sistem atau alat yang sudah dibuat dan dibangun dilanjutkan dengan menguji pada tingkat kelayakan pada alat apakah bisa digunakan dengan baik dan benar atau tidak.

Urutan dari Proses diatas, dapat dilihat pada gambar 1 berikut : 


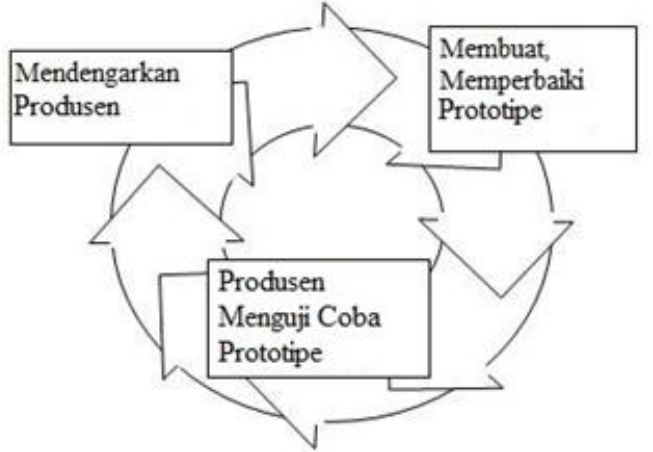

Gambar 1. Urutan metode penelitian

Adapun urutan dari metode kegiatan yang akan dilakukan oleh penulis, dapat dilihat pada diagram Gambar 2 berikut :

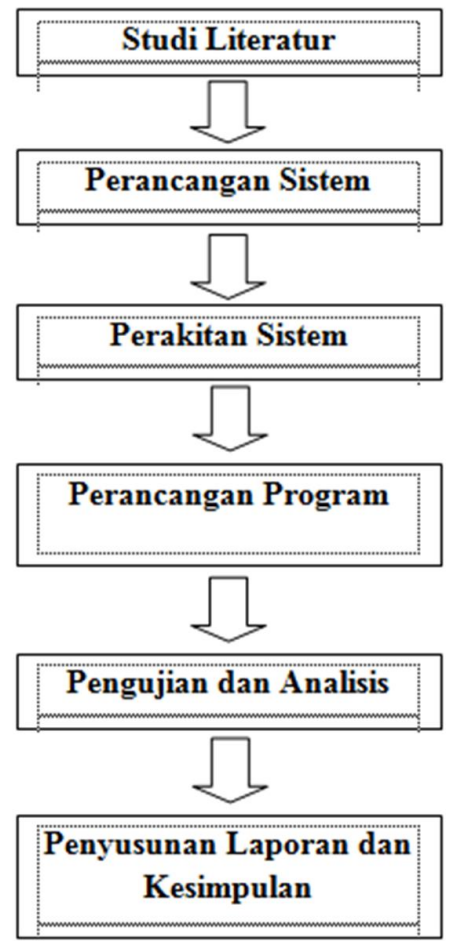

Gambar 2. Urutan metode kegiatan penulis

\subsubsection{Studi Literatur}

Pada tahap pertama dilakukan penelusuran dan mengumpulkan referensi buku-buku/literatur mengenai :

a. Tutorial pemrograman Bahasa $\mathrm{C}$ arduino

b. Modul sms gateway SIM900A

c. Modul sensor suhu dan kelembaban SHT11

d. Elektronika Terintegrasi

e. PWM (Pulse Width Modulation)

Pada metode ini, penulis mengumpulkan data dan informasi dengan cara membaca referensi buku pustaka dan catatan kuliah, serta informasi dari internet terutama untuk materi yang berhubungan dengan masalah sms gateway dan monitoring suhu dan kelembaban menggunakan sht11.

\subsubsection{Perancangan dan Perakitan Sistem}

Pada tahap ini akan dijelaskan tentang perancangan sistem monitoring suhu dan kelembaban proses fermentasi tempe, perancangan prototype pada penelitian ini menjadi dua bagian proses sebagai berikut :

1. Perancangan perangkat keras (hardware)

2. Perancangan perangkat lunak (software)

\subsubsection{Perancangan Perangkat Keras (hardware)}

Pada metode ini, penulis melakukan perancangan untuk pembuatan sistem berupa sistem rangkaian elektronika, mekanik sebagai peletakan semua perangkat keras.

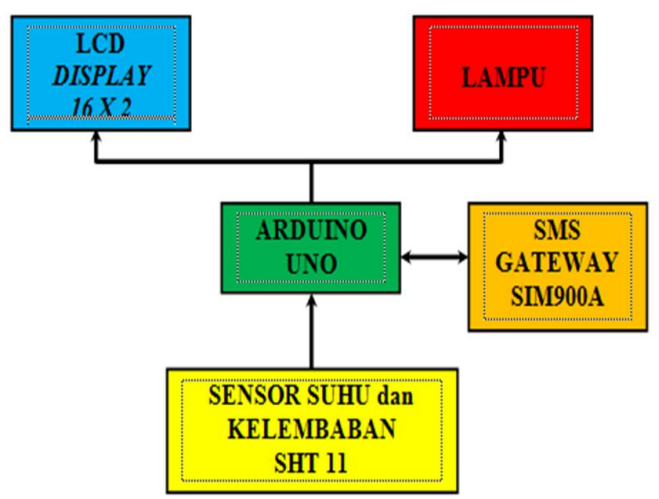

Gambar 3. Blok Diagram

Cara Kerja Sistem :

1. Untuk menyalakan sistem tersedia tombol yang mempunyai fungsi on/off dengan maksud mengalirkan tegangan keseluruh sistem yang diantaranya yaitu mikrokontroler (Arduino UNO), sensor suhu dan kelembaban sht11, modul sms gateway SIM900A, lampu, dan modul LCD. Dalam sistem ini menggunakan adaptor power supply untuk menjalankan keseluruhan sistem dalam proses fermentasi tempe.

2. Otak sistem kontrol menggunakan mikrokontroler arduino UNO. Mikrokontroler sebagai kontrol utama sistem untuk menginisialisasi port baik itu input maupun output.

3. Sebagai input (masukan) dalam sistem yaitu suhu dan kelembaban sht11 sebagai deteksi suhu dan kelembaban pada ruangan. 
4. Sebagai komunikasi serial dalam sistem yaitu modul sms gateway SIM900A sebagai pengirim data suhu dan kelembaban dan penerima perintah monitoring suhu dan kelembaban ruangan.

5. Sebagai output (keluaran) yaitu modul LCD Display sebagai keluaran karakter atau tulisan dan lampu sebagai keluaran cahaya untuk pengontrolan suhu dan kelembaban pada ruangan.

Perancangan perangkat keras (hardware) keseluruhan sistem :

Berikut keseluruhan perancangan perangkat keras (hardware) sebagai kontrol utama yaitu terdiri dari mikrokontroler arduino uno, sensor suhu dan kelembaban ruangan, modul sms gateway, relay, module stepdown, dan LCD display $16 \times 2$.

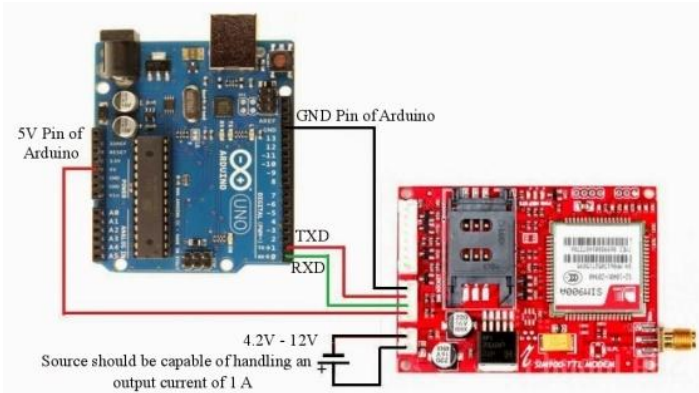

Gambar 4. Konfigurasi Arduino Uno dengan SIM900A

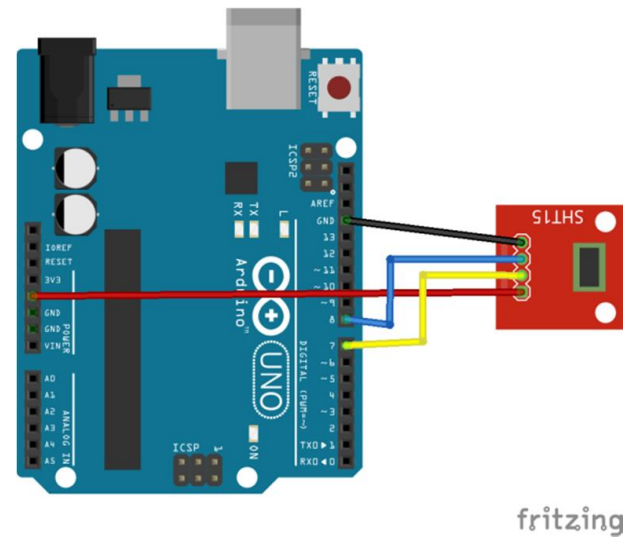

Gambar 5. Konfigurasi Arduino Uno dengan SHT11

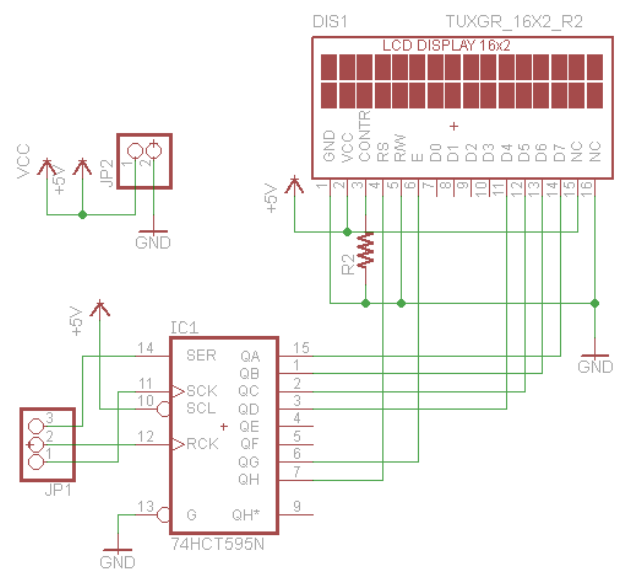

Gambar 6. Perancangan Rangkaian Shift Register LCD Display $16 \times 2$

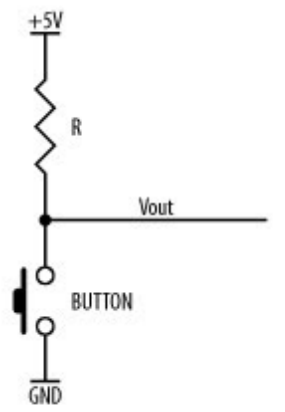

Gambar 7. Perancangan Rangkaian Push Button

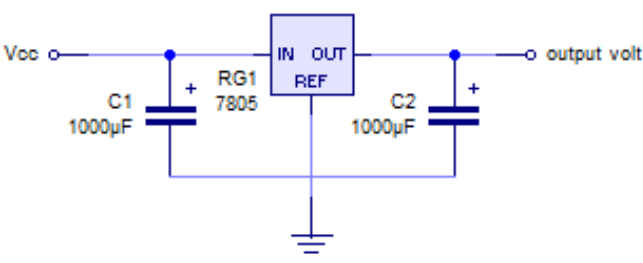

Gambar 8. Perancangan Rangkaian Regulator Stepdown

\subsubsection{Perancangan Perangkat Lunak (software)}

Cara kerja sistem ini awal sebagai pemulaan sistem yaitu mikrokontroler melakukan identifikasi port input dan output yang sudah diatur melalui program, kemudian melakukan pengaturan pengaturan batas suhu dan kelembaban setelah itu diproses oleh mikrokontroler sehingga mengeluarkan 3 output yaitu tampilan suhu dan kelembaban pada led display, pengiriman sms keterangan suhu melebihi batas dan kelembaban kurang serta lampu sebagai pengontrol suhu dan 
kelembaban dan monitor keterangan suhu dan kelembaban.

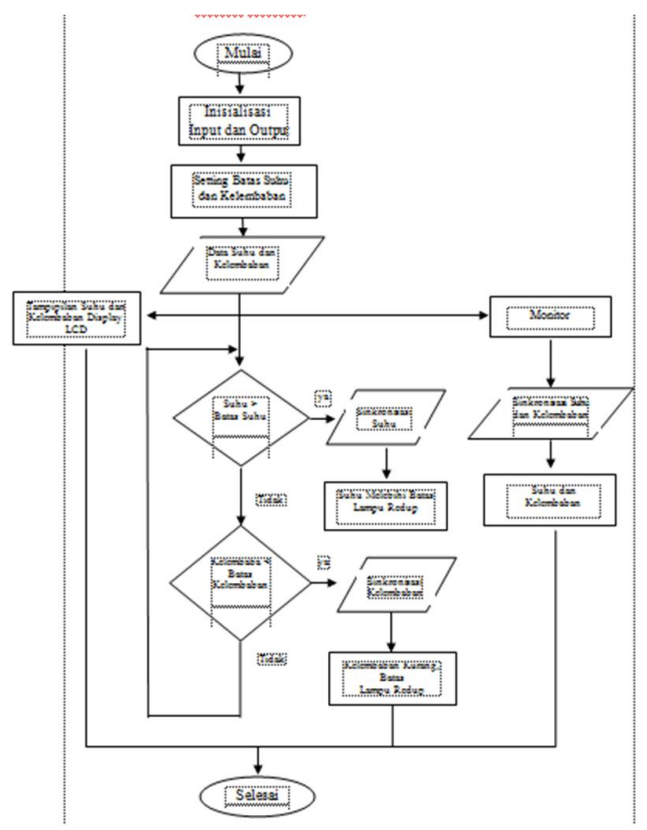

Gambar 9. Perancangan Perangkat Lunak

\subsubsection{Perancangan Program}

Pada metode ini, penulis akan merencanakan program interface ini menggunakan bahasa $\mathrm{C}$ dengan aplikasi pemrograman arduino IDE. Arduino adalah sebuah module mikrokontroler dengan port input dan output yang diprogram menggunakan bahasa $\mathrm{C}$, Arduino Compiler / IDE arduino digunakan untuk mengkompile bahasa $\mathrm{C}$ arduino dan juga untuk mengupload program hasil compile tersebut (hex file) ke board Arduino. Jalankan IDE Arduino dengan menjalankan sebuah file bernama arduino.exe pada lokasi software Arduino

\section{Hasil dan Pembahasan}

\subsection{Pengujian dan Analisa}

Pengujian dan analisa sistem yang telah dibuat, Pengujian ini dilaksanakan untuk mengetahui apakah sistem monitoring dan kontrol sudah sesuai dengan perancangan atau belum dan pengujian dilakukan secara terpisah. lain:

Pengujian yang dilakukan pada bab ini antara

1. Pengujian komunikasi SMS gateway dengan arduino

2. Pengujian sensor suhu dan kelembaban

3. Pengujian display LCD

4. Pengujian relay

5. Pengujian perangkat sistem kontrol

\subsubsection{Pengujian Komunikasi SMS gateway dengan Mikrokontroler}

Pengujian dilakukan dengan menguji koneksi modul SMS gateway dengan mikrokontroler melalui media perangkat mobile (handphone) dengan bentuk sms yang diterima oleh handphone yang dituju.

\subsubsection{Prosedur pengujian}

1. Aktifkan modul sms gateway dan arduino

2. Setelah kedua modul sudah aktif tunggu led/lampu indikator pada modul sms gateway berkedip secara konstan.

3. Cek handphone apakah ada pesan masuk atau tidak.

Tabel 1. Pengujian pengiriman dari SMS gateway ke Handphone

\begin{tabular}{|c|c|c|c|}
\hline \multirow{2}{*}{ No } & Pengiriman & Penerima & \multirow{2}{*}{ Ket } \\
\cline { 2 - 3 } & $\begin{array}{c}\text { Modul SMS gateway } \\
\text { (SIM900A) }\end{array}$ & Handphone & \\
\hline 1 & tes SMS & tes SMS & OK \\
\hline 2 & tes SMS & tes SMS & OK \\
\hline 3 & tes SMS & tes SMS & OK \\
\hline 4 & tes SMS & tes SMS & OK \\
\hline 5 & tes SMS & tes SMS & OK \\
\hline 6 & tes SMS & tes SMS & OK \\
\hline 7 & tes SMS & tes SMS & OK \\
\hline 8 & tes SMS & tes SMS & OK \\
\hline 9 & tes SMS & tes SMS & OK \\
\hline 10 & tes SMS & tes SMS & OK \\
\hline
\end{tabular}

Tabel 2. Pengujian pengiriman Handphone dari ke SMS gateway

\begin{tabular}{|c|c|c|c|}
\hline \multirow{2}{*}{ No } & Pengiriman & Penerima & \multirow{2}{*}{ Ket } \\
\cline { 2 - 3 } & Handphone & $\begin{array}{c}\text { Modul SMS gateway } \\
\text { (SIM900A) }\end{array}$ & \\
\hline 1 & iva & iva & OK \\
\hline 2 & iva & iva & OK \\
\hline 3 & iva & iva & OK \\
\hline 4 & iva & iva & OK \\
\hline 5 & iva & iva & OK \\
\hline 6 & iva & iva & OK \\
\hline 7 & iva & iva & OK \\
\hline 8 & iva & iva & OK \\
\hline 9 & iva & iva & OK \\
\hline 10 & iva & iva & OK \\
\hline
\end{tabular}




\subsubsection{Pengujian Sensor Suhu dan Kelembaban}

Prototype dirancang untuk mengetahui suhu dan kelembaban pada suatu ruangan fermentasi tempe. Sensor suhu dan kelembaban menggunakan SHT11 yang ditempelkan pada ruang fermentasi tempe sehingga bisa mengetahui keadaan suhu dan kelembaban pada ruangan tersebut.

Tabel 3. Pengujian Sensor Suhu dan Kelembapan

\begin{tabular}{|c|c|c|c|}
\hline No & Suhu & Kelembaban & Ket \\
\hline 1 & $27,37^{\circ} \mathrm{C}$ & $85,71 \%$ & OK \\
\hline 2 & $27,38^{\circ} \mathrm{C}$ & $85,77 \%$ & OK \\
\hline 3 & $27,39^{\circ} \mathrm{C}$ & $85,74 \%$ & OK \\
\hline 4 & $27,36^{\circ} \mathrm{C}$ & $85,68 \%$ & OK \\
\hline 5 & $27,38^{\circ} \mathrm{C}$ & $85,66 \%$ & OK \\
\hline 6 & $28,37^{\circ} \mathrm{C}$ & $85,71 \%$ & OK \\
\hline 7 & $29,10^{\circ} \mathrm{C}$ & $85,69 \%$ & OK \\
\hline 8 & $27,50^{\circ} \mathrm{C}$ & $88,54 \%$ & OK \\
\hline 9 & $27,68^{\circ} \mathrm{C}$ & $80,40 \%$ & OK \\
\hline 10 & $28,45^{\circ} \mathrm{C}$ & $88,67 \%$ & OK \\
\hline
\end{tabular}

\subsubsection{Pengujian Display LCD}

Pengujian display karakter LCD 16x2 dilakukan dengan mengamati data suhu dan kelembaban suatu ruangan yang didapat dari sensor sht11 yang diproses oleh mikrokontroler arduino kemudian ditampilkan pada layar LCD.

Tabel 4. Pengujian Display LCD

\begin{tabular}{|c|c|c|c|c|}
\hline No & Suhu & Kelembaban & T ampilan LCD & Ket \\
\hline 1 & $27,37^{\circ} \mathrm{C}$ & $85,71 \%$ & $\begin{array}{l}\text { Suhu : } 27,37^{\circ} \mathrm{C} \\
\text { RH : } 85,71 \%\end{array}$ & $\mathrm{OK}$ \\
\hline 2 & $27,38^{\circ} \mathrm{C}$ & $85,77 \%$ & $\begin{array}{l}\text { Suhu : } 27,38^{\circ} \mathrm{C} \\
\text { RH : } 85,77 \%\end{array}$ & OK \\
\hline 3 & $27,39^{\circ} \mathrm{C}$ & $85,74 \%$ & $\begin{array}{l}\text { Suhu : } 27,39^{\circ} \mathrm{C} \\
\text { RH : } 85,74 \%\end{array}$ & OK \\
\hline b & $28,30^{\circ} \mathrm{C}$ & $85,77 \%$ & $\begin{array}{l}\text { Suhu : } 28,30^{\circ} \mathrm{C} \\
\text { RH : } 85,77 \%\end{array}$ & OK \\
\hline 5 & $28,35^{\circ} \mathrm{C}$ & $85,74 \%$ & $\begin{array}{l}\text { Suhu : } 28,35^{\circ} \mathrm{C} \\
\text { RH : } 85,74 \%\end{array}$ & $\mathrm{OK}$ \\
\hline 6 & $28,37^{\circ} \mathrm{C}$ & $85,71 \%$ & $\begin{array}{l}\text { Suhu : } 28,37^{\circ} \mathrm{C} \\
\text { RH : } 85,71 \%\end{array}$ & $\mathrm{OK}$ \\
\hline 7 & $29,10^{\circ} \mathrm{C}$ & $85,69 \%$ & $\begin{array}{l}\text { Suhu : } 29,10^{\circ} \mathrm{C} \\
\text { RH : } 85,69 \%\end{array}$ & $\mathrm{OK}$ \\
\hline 8 & $27,50^{\circ} \mathrm{C}$ & $88,54 \%$ & $\begin{array}{l}\text { Suhu : } 27,50^{\circ} \mathrm{C} \\
\mathrm{RH}: 88,54 \%\end{array}$ & $\mathrm{OK}$ \\
\hline 9 & $27,68^{\circ} \mathrm{C}$ & $80,40 \%$ & $\begin{array}{l}\text { Suhu : } 27,68^{\circ} \mathrm{C} \\
\text { RH : } 80,40 \%\end{array}$ & $\mathrm{OK}$ \\
\hline 10 & $28,45^{\circ} \mathrm{C}$ & $88,67 \%$ & $\begin{array}{l}\text { Suhu : } 28,45^{\circ} \mathrm{C} \\
\text { RH : } 88,67 \%\end{array}$ & OK \\
\hline
\end{tabular}

\subsubsection{Pengujian Relay}

Relay yang digunakan berjumlah 2 buah module, secara umum relay adalah sakelar listrik yang membuka atau menutup aliran listrik pada rangkaian dalam kondisi tertentu. Jadi pada prototype ini relay berfungsi memutus dan menyambungkan aliran listrik pada kipas dan tegangan $220 \mathrm{~V}$ untuk lampu.

Tabel 5. Pengujian Relay

\begin{tabular}{|c|c|c|c|c|}
\hline No & Kondisi & Relay l & Relay 2 & Ket \\
\hline 1 & 0 & OFF & OFF & OK \\
\hline 2 & 1 & ON & ON & OK \\
\hline 3 & 0 & OFF & OFF & OK \\
\hline 4 & 1 & ON & ON & OK \\
\hline 5 & 0 & OFF & OFF & OK \\
\hline 6 & 1 & ON & ON & OK \\
\hline 7 & 0 & OFF & OFF & OK \\
\hline 8 & 1 & ON & ON & OK \\
\hline 9 & 0 & OFF & OFF & OK \\
\hline 10 & 1 & ON & ON & OK \\
\hline
\end{tabular}

\subsubsection{Pengujian perangkat sistem kontrol}

Pengujian sistem kontrol merupakan pengujian dari keseluruhan komponen yang terdapat pada alat ini. Perangkat masukan dalam sistem ini yaitu sensor suhu dan kelembaban sht11 dan komunikasi serial yaitu pada modul sms gateway sim900a dengan keluaran atau output yaitu display lcd 16x2 dan lampu.

Tabel 6. pengujian sistem kontrol dengan perintah monitor

\begin{tabular}{|c|c|c|c|c|c|}
\hline No & Suhu & $\begin{array}{c}\text { Kelemb } \\
\text { aban }\end{array}$ & Display LCD & $\begin{array}{l}\text { SMS pada } \\
\text { handphone }\end{array}$ & Ket \\
\hline 1 & $25^{\circ} \mathrm{C}$ & $80 \%$ & $\begin{array}{l}\text { Suhu : } 25^{\circ} \mathrm{C} 25 \\
\mathrm{RH}: 80 \% \quad 80\end{array}$ & $\begin{array}{l}\text { Temperatur }=25^{\circ} \mathrm{C} \\
\text { Humaditx }=80 \%\end{array}$ & $\mathrm{OK}$ \\
\hline 2 & $24{ }^{\circ} \mathrm{C}$ & $84 \%$ & $\begin{array}{l}\text { Suhu : } 24^{\circ} \mathrm{C} \quad 25 \\
\text { RH : } 84 \% \quad 80\end{array}$ & $\begin{aligned} \text { Temperatur } & =24{ }^{\circ} \mathrm{C} \\
\text { Humadity } & =84 \%\end{aligned}$ & $\mathrm{OK}$ \\
\hline 3 & $30^{\circ} \mathrm{C}$ & $70 \%$ & $\begin{array}{l}\text { Suhu: } 30^{\circ} \mathrm{C} 25 \\
\text { RH : } 70 \% \quad 80\end{array}$ & $\begin{aligned} \text { Temperatur } & =30^{\circ} \mathrm{C} \\
\text { Humaditx } & =70 \%\end{aligned}$ & $\mathrm{OK}$ \\
\hline 4 & $31^{\circ} \mathrm{C}$ & $62 \%$ & $\begin{array}{l}\text { Suhu : } 31^{\circ} \mathrm{C} \quad 25 \\
\text { RH : } 62 \% \quad 80\end{array}$ & $\begin{array}{l}\text { Temperatur }=31^{\circ} \mathrm{C} \\
\text { Humaditx }=62 \%\end{array}$ & $\mathrm{OK}$ \\
\hline 5 & $27^{\circ} \mathrm{C}$ & $72 \%$ & $\begin{array}{l}\text { Suhu : } 27^{\circ} \mathrm{C} \quad 25 \\
\text { RH : } 72 \% \text { 80 }\end{array}$ & $\begin{array}{l}\text { Temperatur }=27^{\circ} \mathrm{C} \\
\text { Humadity }=72 \%\end{array}$ & $\mathrm{OK}$ \\
\hline 6 & $28^{\circ} \mathrm{C}$ & $68 \%$ & $\begin{array}{l}\text { Suhu : } 28^{\circ} \mathrm{C} \quad 25 \\
\mathrm{RH}: 68 \% \quad 80\end{array}$ & $\begin{array}{l}\text { Temperatur }=28^{\circ} \mathrm{C} \\
\text { Humaditx }=68 \%\end{array}$ & $\mathrm{OK}$ \\
\hline 7 & $29^{\circ} \mathrm{C}$ & $67 \%$ & $\begin{array}{l}\text { Suhu : } 29^{\circ} \mathrm{C} \quad 25 \\
\text { RH : } 67 \% \text { S0 }\end{array}$ & $\begin{array}{l}\text { Temperatur }=29^{\circ} \mathrm{C} \\
\text { Humaditx }=67 \%\end{array}$ & $\mathrm{OK}$ \\
\hline 8 & $28^{\circ} \mathrm{C}$ & $66 \%$ & $\begin{array}{l}\text { Suhu : } 28^{\circ} \mathrm{C} \quad 25 \\
\mathrm{RH}: 66 \% \quad 80\end{array}$ & $\begin{array}{l}\text { Temperatur }=28^{\circ} \mathrm{C} \\
\text { Humaditx }=66 \%\end{array}$ & $\mathrm{OK}$ \\
\hline 9 & $26^{\circ} \mathrm{C}$ & $80 \%$ & $\begin{array}{l}\text { Suhu : } 26^{\circ} \mathrm{C} \quad 25 \\
\text { RH : } 80 \% \quad 80\end{array}$ & $\begin{array}{l}\text { Temperatur }=26^{\circ} \mathrm{C} \\
\text { Humaditx }=80 \%\end{array}$ & $\mathrm{OK}$ \\
\hline 10 & $25^{\circ} \mathrm{C}$ & $84 \%$ & $\begin{array}{l}\text { Suhu : } 25^{\circ} \mathrm{C} \quad 25 \\
\mathrm{RH}: 84 \% \quad 80\end{array}$ & $\begin{array}{l}\text { Temperatur }=25^{\circ} \mathrm{C} \\
\text { Humaditx }=84 \%\end{array}$ & $\mathrm{OK}$ \\
\hline
\end{tabular}


Tabel 7. Pebandingan proses fermentasi dengan alat dan tanpa alat

\begin{tabular}{|c|c|c|c|c|}
\hline \multirow{2}{*}{ No } & \multicolumn{2}{|c|}{ Dengan Alat } & \multicolumn{2}{|c|}{ Tanpa Alat } \\
\hline & Jam & Keterangan & Jam & Keterangan \\
\hline 1 & $10.00-16.00$ & Mentah & $10.00-19.00$ & Mentah \\
\hline 2 & $17.00-22.00$ & $\begin{array}{l}\text { Tumbuh Jamur } \\
\text { Sebagian }\end{array}$ & $20.00-03.00$ & $\begin{array}{l}\text { Tumbuh Jamur } \\
\text { Sebagian }\end{array}$ \\
\hline 3 & $23.00-04.00$ & Tumbuh Jamur Full & $04.00-09.00$ & Tumbuh Jamur Full \\
\hline
\end{tabular}

Dengan perbedaan dari hasil tabel penelitian fermentasi tempe diatas dengan menggunakan alat dan tanpa menggunakan alat menghasilkan tempe yang baik hanya berbeda waktu proses fermnetasi. Proses fermentasi tempe yang menggunakan alat dari pukul 10:00 WIB sampai pukul 04:00 WIB sedangkan proses fermentasi tempe tanpa menggunakan alat dari pukul 10:00 WIB sampai pukul 09:00 WIB. Jadi dari penelitian proses fermentasi tempe menggunakan alat lebih cepat dibandingkan tanpa menggunakan alat.

\section{Kesimpulan}

Setelah sistem monitoring suhu dan kelembaban pada proses fermentasi tempe berfunfsi dengan semestinya maka, segala bentuk yang berhubungan dengan perakitan dan perancangan hingga analisa sistem telah tertulis pada laporan penelitian dapat di simpulkan bahwa:

1. Sistem monitoring suhu dan kelembaban pada proses fermentasi tempe di rancang dan di buat dengan menggunakan sensor SHT11 yang dapat bekerja dengan baik.

2. Monitoring suhu dan kelembaban dengan jarak jauh menguunakan sms gateway sim900a sebagai ic (integrated circuit) untuk memproses pengiriman keterangan suhu dan kelembaban dan menerima perintah monitor dari handphone.

3. Pengontrolan lampu secara otoamtis untuk mengontrol suhu pada inkubator fermentasi tempe dengan menggunakan sistem Relay 2 lampu.

\section{Daftar Pustaka:}

Agusra.2011. ARTIKEL dan MAKALAH lengkap.Kelembaban

http://artikeldanmakalahagusra.blogspot.co.id/2011/06/kelembaban.ht $\mathrm{ml}$ [13 Juni 2016]

Agus, Bejo. 2007. C \& AVR Rahasia Kemudahan Bahasa $C$ dalam MikrokontrolerATMega8535. Yogyakarta. Graha Ilmu. [13 Juni 2016]

Andris_faesal. 2012. Belajar_IT SMS Gateway. http://andrisfaesal.blogspot.co.id/2012/01/apaitu-sms-gateway.html [27Juni2016]

George R. Tery .2006:395.MONITORING ( PENGAWASAN http://riatiofanta.blogspot.co.id/2014/12/monit oring-pengawasan.html [15 Juni 2016]

Kamuskimia.balai pustaka.2002.Pengertian SuhudalamIlmuFisika. BorderSEO. http://www.g-excess.com/pengertian-suhudalam-ilmu-fisika.html. [16 Juni 2016]

Satiawihardja .1992.Sharing + Solution.FERMENTASI.

http://risna-unsrichem.blogspot.co.id/2013/03/1.html [20 Juni 2016] 
Volume 4, Edisi 1, November 2017

$\mathbf{5 6} \mid \mathrm{H}$ a 1 a $\mathrm{m}$ a $\mathrm{n}$ 